\title{
Integrated working fluid-thermodynamic cycle design of organic Rankine cycle power systems for waste heat recovery
}

Cignitti, Stefano; Andreasen, Jesper Graa; Haglind, Fredrik; Woodley, John; Abildskov, Jens

Published in:

Applied Energy

Link to article, DOI:

10.1016/j.apenergy.2017.06.031

Publication date:

2017

Document Version

Peer reviewed version

Link back to DTU Orbit

Citation (APA):

Cignitti, S., Andreasen, J. G., Haglind, F., Woodley, J., \& Abildskov, J. (2017). Integrated working fluidthermodynamic cycle design of organic Rankine cycle power systems for waste heat recovery. Applied Energy, 203, 442-453. https://doi.org/10.1016/j.apenergy.2017.06.031

\section{General rights}

Copyright and moral rights for the publications made accessible in the public portal are retained by the authors and/or other copyright owners and it is a condition of accessing publications that users recognise and abide by the legal requirements associated with these rights.

- Users may download and print one copy of any publication from the public portal for the purpose of private study or research.

- You may not further distribute the material or use it for any profit-making activity or commercial gain

- You may freely distribute the URL identifying the publication in the public portal 


\title{
Integrated working fluid-thermodynamic cycle design of organic Rankine cycle power systems for waste heat recovery
}

\author{
Stefano Cignitti ${ }^{\mathrm{a}}$, Jesper G. Andreasen ${ }^{\mathrm{b}}$, Fredrik Haglind ${ }^{\mathrm{b}}$, John M. Woodley ${ }^{\mathrm{a}}$, Jens Abildskov ${ }^{\mathrm{a}}$ \\ ${ }^{a}$ Process and Systems Engineering Center (PROSYS), Department of Chemical and Biochemical \\ Engineering, Technical University of Denmark, Building 229, 2800 Kgs. Lyngby, Denmark \\ ${ }^{b}$ Department of Mechanical Engineering, Technical University of Denmark, \\ Building 403, 2800 Kgs. Lyngby, Denmark
}

\begin{abstract}
Today, some established working fluids are being phased out due to new international regulations on the use of environmentally harmful substances. With an ever-increasing cost to resources, industry wants to converge on improved sustainability through resource recovery, and in particular waste heat recovery. In this paper, an organic Rankine cycle process and its pure working fluid are designed simultaneously for waste heat recovery of the exhaust gas from a marine diesel engine. This approach can overcome design issues caused by the high sensitivity between the fluid and cycle design variables and otherwise high resource demands, which through conventional methods cannot be addressed. The global optimal design was a $1.2 \mathrm{MW}$ cycle with 2,2,3,3,4,4,5,5-octafluorohexane as the new fluid. The fluid has no ozone depletion potential and a global warming potential under the regulatory limit. By using the simultaneous design approach the optimum solution was found in 5.04 seconds, while a decomposed approach found the same solution in 5.77 hours. However, the decomposed approach provided insights on the correlation between the fluid and cycle design variables by analyzing all possible solutions. It was shown that the high sensitivity between the fluid and cycle design variables was overcome by using the simultaneous approach. Correlation between net power output and the product of the overall heat transfer coefficient and the heat transfer area could further be addressed by employing a new solution strategy including maximum constraints for this product. The use of such constraints resulted in the design of a new fluid (5-chloro-4,5,5-trifluoro-2,3-dimethylpent-2-ene) with a $1.25 \mathrm{MW}$ net power output. Finally, a comparison with conventional fluids was shown where 2,2,3,3,4,4,5,5octafluorohexane offered an improvement on net power output and economic and environmental metrics.
\end{abstract}

Keywords: Integrated design; optimization; CAMD; organic Rankine cycle; working fluid; waste heat; 


\section{Nomenclature}

\section{Symbol}

A Heat transfer area $\left(\mathrm{m}^{2}\right)$

$\mathbf{C}_{\mathbf{p}, \mathbf{A}} \quad$ Ideal gas heat capacity parameter

$\mathbf{C}_{\mathbf{p}, \mathbf{B}} \quad$ Ideal gas heat capacity parameter

$\mathbf{C}_{\mathbf{p}, \mathbf{C}} \quad$ Ideal gas heat capacity parameter

$\mathbf{C}_{\mathbf{p}, \mathbf{D}} \quad$ Ideal gas heat capacity parameter

$\mathbf{C}_{\mathbf{p}, \mathbf{i g}} \quad$ Ideal gas heat capacity $(\mathrm{J} / \mathrm{mol} / \mathrm{K})$

$\mathbf{F}_{\mathbf{r}} \quad$ Flow rate working fluid $(\mathrm{mol} / \mathrm{h})$

GWP Global warming potential (CO2eq)

h $\quad$ Enthalpy $(\mathrm{J} / \mathrm{mol})$

n Number of group

ODP Ozone depletion potential (R11eq)

$\mathbf{P} \quad$ Pressure (bar)

$\mathbf{P}_{\mathbf{c}} \quad$ Critical pressure (bar)

q Molecular structure type

s $\quad$ Entropy $(\mathrm{J} / \mathrm{mol} / \mathrm{K})$

T Temperature (K)

$\mathbf{T}_{\mathbf{c}} \quad$ Critical temperature (K)

U Overall heat transfer coefficient $\left(\mathrm{W} / \mathrm{m}^{2} / \mathrm{K}\right)$

v Valency

$\dot{\mathbf{W}}_{\text {net }} \quad$ Net power output $(\mathrm{J} / \mathrm{h})$

Z Compressibility

$\varphi \quad$ Fugacity coefficient

$\Psi, \Omega \quad$ Equation of state parameter

$\omega \quad$ Acentric factor

\section{Superscript}

U Upper bound

L Lower bound

Subscript

g Exhaust gas

i $\quad$ Group set

LMTD Logarithmic mean temperature difference

ph Phase set

Isentropic process

Stream/stage set

Cooling sea water 


\section{Introduction}

Recovering waste heat from processes requires significant effort in the design and optimization of the working fluid as well as the thermodynamic cycle. Environmental regulations have been a driving force for the industry to seek novel working fluids since many conventional fluids are being phased out. This follows the Kyoto Protocol in 1997 and more recently new EU regulations from 2014 [1,2], which restrict the use of some working fluids currently in use [3]. However, design of a new working fluid poses a challenge and finding an optimum solution for a given application often results in a trade-off between cycle performance, and environmental and safety criteria. Furthermore, low-temperature (low-grade) waste heat sources pose additional challenges to make the recovery technically and economically feasible [4-6]. Amonst others, hydrofluoroolefins (HFOs) have been suggested as a potential future class of low global warming potential working fluids. However, data for such fluids is scarce in conventional databases [7-10]. These issues have led to the development of several methods and tools for designing new working fluids and organic Rankine cycle (ORC) power systems.

Most of these methods are based on computer-aided molecular design techniques (CAMD) to design alternative or novel working fluids [11]. Papadopoulos et al. (2012, 2010a, 2010b) proposed a systematic design approach for working fluid generation for ORC units. Here, a weighted objective function based on scaled pure properties was proposed and used. As reported in their work, ten pure fluid properties are influential in the cycle performance and in the feasibility of the solution. Specifically, three of these process metrics are important to optimize. Initially [12], the authors used the weighted objective function employing all of the important pure fluid properties. Subsequently, the problem was reformulated into a multi-objective optimization problem considering only five of the pure fluid properties [13]. Finally, the cycle performance was evaluated for one or more solutions. Palma-Flores et al. (2015) also proposed a method for choosing the optimal pure working fluid for an ORC unit using a CAMD approach. The objective function here was based on temperature dependent pure fluid properties.

Other authors have taken approaches which avoid CAMD method and start either with a set of chosen fluids or apply a reverse engineering approach. For example, Andreasen et al. (2014) proposed a methodology for working fluid selection for an ORC unit for use of low-temperature heat. Thirty pure and mixed working fluids were selected through optimization of the ORC unit. The fluids were ranked according to the objective function, which was the cycle net power output. Likewise a reversed engineering approach can be employed, where the optimal fluid properties are found through an optimization problem without regard tochemical feasibility or stability of the molecule. Molecules that then match these properties are found in a subsequent step. Such methods have been reported in several works and frequently such a solution approach has been found necessary due to the complexity of the thermodynamic model employed [17-19]. These methods are usually termed a continuous-molecular targeting approach (CoMT-CAMD). The works presented tend to optimize all the fluid properties, which is a difficult task, given the correlation between properties that may make the result in local optima [5,20]. The issue of correlated properties also holds true when considering the detailed design of certain components in the ORC unit that cannot solely be based on primary fluid properties [21].

The current state-of-the-art offers methods for designing fluids for organic Rankine cycle units from a sequential (or decomposed) approach, where the working fluid design and process optimization are carried out in separate steps. This results in sub-optimal solutions on account of high correlation between fluid and process variables. In this way, the methods are not able to obtain a global optimal design of working fluid and process. 
In contrast, in the work we report here, for the first time, a simultaneous approach is prposed for integrated pure working fluid and process design for organic Rankine cycle power systems. We reasoned that such an approach would have the benefit of : i) a pre-screening step to avoid a sub-optimal starting point, ii) the design of alternative or new fluids that are environmentally friendly and have similar or improved cycle performance compared to conventional fluids, iii) a rapid search for the global optimum. The approach is based on the use of CAMD, property prediction and mathematical programming techniques to define the fluid-process targets and models, which are combined and solved simultaneously. Additionally we have included for the first time the design of bicyclic and branched cyclic molecules using CAMD.

This paper will first present the problem description, followed by the approach used and the models needed. Subsequently, the results for the simultaneous design strategy are presented and compared to a decomposed design strategy. The discussion section focusses on the sensitivity of the design variables, the advantage of the simultaneous approach, and on whether the global optimum is found. Finally, the novel fluid resulting from the optimization is compared to conventional fluids.

\section{Methods}

The integrated method employed in this work is summarized in the workflow shown in Figure 1. Several methods were used to simultaneously design alternative or novel working fluids for the organic Rankine cycle process. CAMD was used to enable a model-based description as reported previously(Cignitti et al. (2015) and Zhang et al. (2015)). Meanwhile, the cycle itself was described through classical mass and energy balances. Fluid properties (enthalpy (h), entropy (s) and fugacity $(\varphi)$ ), were predicted using the Soave-Redlich-Kwong (SRK) equation of state (EoS) [23].

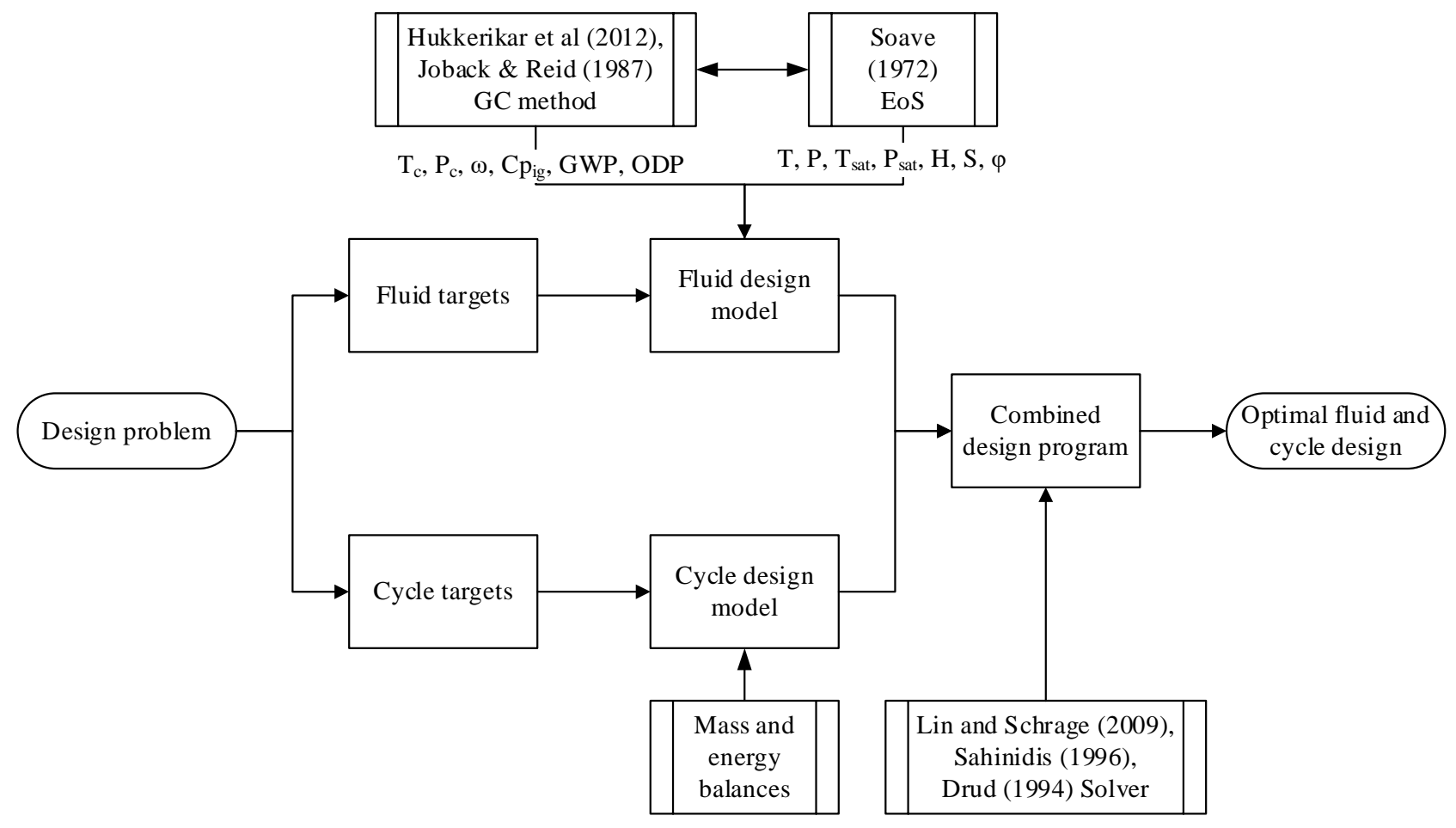

Figure 1: Integrated design workflow 
The pure fluid properties were predicted by group contribution (GC) methods that calculate the properties from the molecular structure of the working fluids. For this, the method of Hukkerikar et al. (2012) was used to predict critical properties and the acentric factor. The method of Joback and Reid (1987) was used to predict the ideal gas heat capacity. Finally, the method of Hukkerikar et al. (2012) was used to calculate any missing group contributions for some groups and for the prediction of global warming potential (GWP) and ozone depletion potential (ODP). The GWP and ODP give a good indication whether or not the fluid complies with refrigerant regulations [2].

The fluid and process design methods were applied to the design of an ORC unit which was proposed for waste heat recovery from internal combustion engines, [26-28]. In the case studied here the waste heat originated from a 37 MW marine diesel engine (model: 7G95ME-C9.5 with LP SCR \& EGB tuning [29]) from MAN Diesel \& Turbo. Marine diesel engines produced significant amount of waste heat from exhaust gasses which can potentially be recovered for electricity generation. The resulting electricity could meet the electricity demand on the ship, cooling of ship containers or reducing the shaft work for propelling the ship. In all cases, the result would be a significant reduction in fuel consumption by reducing the load on main or auxiliary engines.

To match the cycle, a fluid also needs to be selected. The fluid should enable a high production of electricity and respect environmental and safety regulations. On this premise it was decided to search for acyclic, alicyclic and aromatic hydrocarbons that contain double bonds, fluorine and maximum one chlorine atom if fluorine and double bonds were present. This ensurs that the designed fluid has a low global warming potential and ozone depletion potential.. The selection was based on common fluids utilized in such cycles [16] and on guidelines from regulations [2,3].

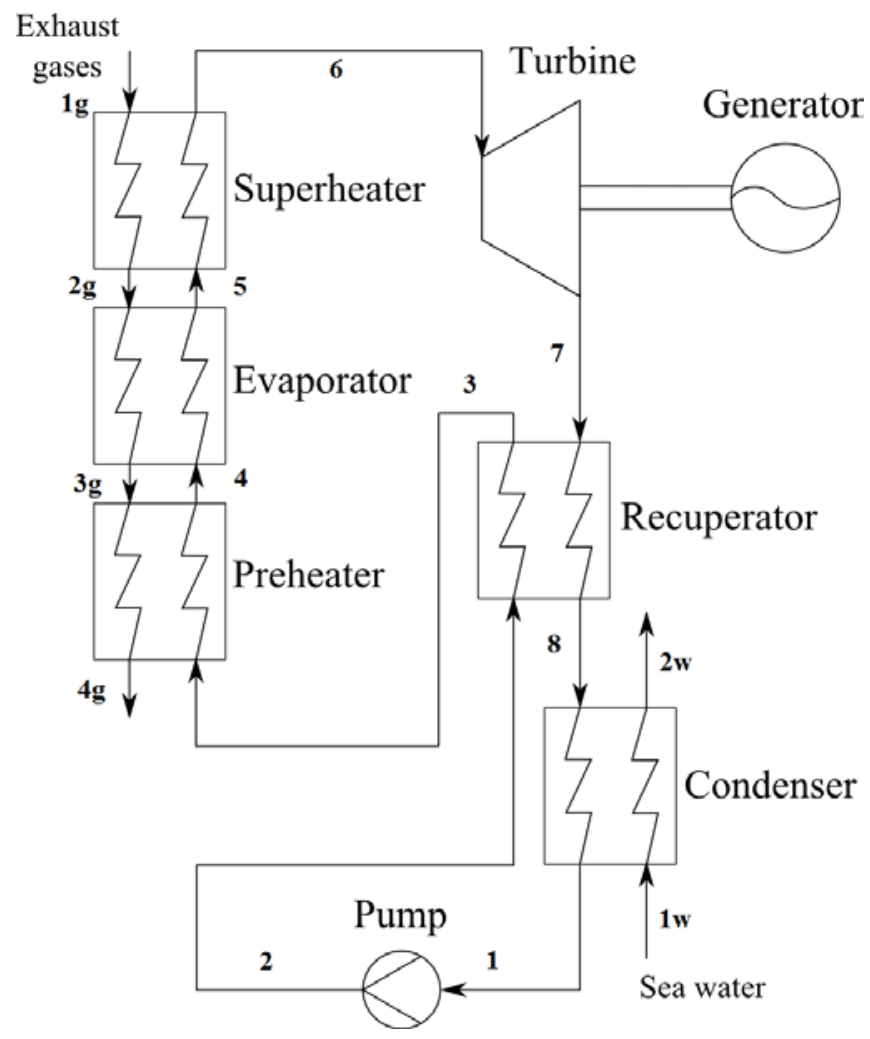

Figure 2: Flowsheet of the ORC unit with recuperator. 
A flowsheet of the ORC system is given in Figure 2. The ORC unit contains a turbine, recuperator, condenser, pump and boiler. Here, the boiler is divided into three sections: preheater, evaporator and super-heater. A configuration with a recuperator was chosen such that the feed temperature of working fluid to the boiler is high. The modeling conditions used for the ORC unit are provided in Table 1. The design of the ORC unit was considered at the $75 \%$ load point of the diesel engine. The mass flow rate and the temperature of the exhaust gases were obtained from the CEAS engine calculation tool [29]. In order to accommodate on-board heating demands, for example fuel preheating, fuel tank heating and space heating, the exhaust gases were used to generate $2000 \mathrm{~kg} / \mathrm{h}$ of service steam at 7 bar prior to entering the ORC unit boiler. In this way, the temperature of the exhaust gas was reduced by around $21 \mathrm{~K}$. The exhaust gas temperature denoted in Table 1 is the temperature after the service steam boiler. The values indicate that $35 \mathrm{MW}$ of heat was contained in the exhaust gas given the assumption of constant heat capacity. The efficiencies $(\eta)$ for the pump and turbine are isentropic efficiencies. The seawater temperatures were fixed at $294 \mathrm{~K}$ at the inlet and $299 \mathrm{~K}$ at the outlet.

Table 1: ORC process operation and parameters

\begin{tabular}{|l|l|l|}
\hline Parameter & Value & Unit \\
\hline $\mathbf{T}_{\mathbf{1 g}}$ & 509 & $\mathrm{~K}$ \\
\hline $\mathbf{C}_{\mathbf{p g}}$ & 31.86 & $\mathrm{~J} / \mathrm{mol} . \mathrm{K}$ \\
\hline $\mathbf{F}_{\mathbf{g}}$ & 2161.15 & $\mathrm{~mol} / \mathrm{s}$ \\
\hline $\mathbf{T}_{\mathbf{1 w}}$ & 294 & $\mathrm{~K}$ \\
\hline $\mathbf{T}_{\mathbf{w}}$ & 299 & $\mathrm{~K}$ \\
\hline $\boldsymbol{\eta}_{\mathbf{p u m p}}$ & 0.7 & - \\
\hline $\boldsymbol{\eta}_{\text {turbine }}$ & 0.8 & - \\
\hline
\end{tabular}

From the problem statement, the fluid and cycle targets were defined.

\subsection{Fluid targets}

Based on an analysis of working fluid databases [7,30] the following target properties were chosen, summarized in Table 2. The bounds for critical temperature $\left(\mathrm{T}_{c}\right)$, critical pressure $\left(\mathrm{P}_{\mathrm{c}}\right)$ and acentric factor $(\omega)$ are large in order not to restrict the search space,. Previous studies suggest that it is not possible to restrict the search space by confining the values of these three properties, let alone the value of ideal gas heat capacity $\left(\mathrm{C}_{\mathrm{p}, \mathrm{ig}}\right)$, since a global sensitivity analysis indicates no clear relationship between these properties and the ORC unit performance [31]. This was then a further argument for employing a CAMD method rather than a database search method, because it would require a combinatorial evaluation of all possible database entries. For the same reason, $\mathrm{C}_{\mathrm{p}, \mathrm{ig}}$ was not bounded, and Global Warming Potential (GWP) and Ozone Depletion Potential (ODP) are inherently addressed at the product type selection, however. All three properties were kept as constitutive variables and models were therefore required for their calculation.

Table 2: Target molecular properties

\begin{tabular}{|l|l|l|l|}
\hline Property & Lower bound & Upper bound & Unit \\
\hline $\mathbf{T}_{\mathbf{c}}$ & 368 & 600 & $\mathrm{~K}$ \\
\hline $\mathbf{P}_{\mathbf{c}}$ & 18 & 100 & $\mathrm{Bar}$ \\
\hline $\boldsymbol{\omega}$ & 0 & 1 & - \\
\hline $\mathbf{C}_{\mathbf{p}, \mathbf{i g}}$ & - & - & $\mathrm{J} / \mathrm{mol.K}$ \\
\hline ODP & 0 & - & eqR11 \\
\hline GWP & 0 & - & eqCO \\
\hline Structure & & & \\
\hline
\end{tabular}




\subsection{Cycle targets}

\begin{tabular}{|l|l|l|l|}
\hline $\mathbf{n}$ & 3 & 9 & - \\
\hline $\mathbf{n}_{\mathbf{i 1}}$ & 0 & 9 & \\
\hline $\mathbf{n}_{\text {branch }}$ & 0 & 9 & \\
\hline $\mathbf{q}$ & -1 & 1 & \\
\hline
\end{tabular}

In order to ensure feasible cycle results, the process variable specifications shown in Table 3 were selected. It was assumed that the sulfur content in the fuel was $3 \%$ (by weight) giving a sulfuric acid dew point of $135^{\circ} \mathrm{C}$ [32]. The lower bound for the boiler feed temperature was therefore selected as $\left(T_{3}=408 \mathrm{~K}\right)$ to ensure that the minimum temperature in the exhaust gas boiler was always above the sulfuric acid dew point. By employing a high lower bound for the boiler feed temperature, it was necessary to recover a significant amount of heat in the recuperator. This was only possible for a few conventional fluids with very dry characteristics sich as Hexamethyldisiloxane (MM) [33]. Seawater was used as the cooling fluid in the condenser.

Table 3: ORC unit specifications

\begin{tabular}{|c|c|c|c|c|}
\hline Variable & Lower bound & Upper bound & Fixed Value & Unit \\
\hline$\Delta \mathbf{T}_{6,5}$ & 10 & 50 & & $\mathrm{~K}$ \\
\hline$\Delta T_{\text {boiler }}$ & 20 & & & K \\
\hline$\Delta T_{\text {recuperator }}$ & 10 & & & K \\
\hline$\Delta \mathbf{T}_{\text {water }}$ & & & 5 & K \\
\hline $\mathbf{T}_{1}$ & 300 & & & K \\
\hline $\mathbf{T}_{3}$ & 408 & & & K \\
\hline $\mathbf{P}_{1}$ & 0.05 & & & bar \\
\hline $\mathbf{P}_{2}$ & & $80 \%$ of $\mathrm{P}_{\mathrm{c}}$ & & bar \\
\hline
\end{tabular}

Furthermore, pressure loses were neglected in the ORC process.

\subsection{Molecular working fluid model}

The CAMD model uses a set of constraints that describe chemically feasible molecules in combination with GC property prediction functions. Among 220 first order groups available from Hukkerikar et al. (2012) the following groups were selected: $\mathrm{CH} 3, \mathrm{CH} 2, \mathrm{CH}, \mathrm{C}, \mathrm{CH} 2=\mathrm{CH}, \mathrm{CH}=\mathrm{CH}, \mathrm{CH} 2=\mathrm{C}, \mathrm{CH}=\mathrm{C}, \mathrm{C}=\mathrm{C}, \mathrm{CF} 3, \mathrm{CF} 2, \mathrm{CF}$, $\mathrm{CH} 2 \mathrm{~F}, \mathrm{CHF}, \mathrm{CHF} 2, \mathrm{HCClF}, \mathrm{CClF} 2, \mathrm{CH} 2$ (сус), $\mathrm{CH}($ сус), $\mathrm{C}($ сус), $\mathrm{CH}=\mathrm{CH}($ сус), $\mathrm{CH}=\mathrm{C}($ сус), $\mathrm{C}=\mathrm{C}($ сус), $\mathrm{CH} 2=\mathrm{C}($ сус $), \mathrm{CF} 2$ сус, $\mathrm{CF} c y c, \mathrm{aCH}, \mathrm{aC}, \mathrm{aC}-\mathrm{CH} 2, \mathrm{aC}-\mathrm{CH}, \mathrm{aC}-\mathrm{CH} 3, \mathrm{aC}-\mathrm{C}, \mathrm{aC}-\mathrm{CH}=\mathrm{CH} 2, \mathrm{aC}-\mathrm{CH}=\mathrm{CH}, \mathrm{aC}-$ $\mathrm{C}=\mathrm{CH} 2$ and aC-F. Through classification of the different structural groups based on their valencies, the octet rule (Eq. 1) provides a simple relation for the structural feasibility of a given collection of groups [34]:

$$
\begin{gathered}
\sum_{i_{2} \in G_{1}}\left(2-v_{i_{1}}\right) n_{i_{1}}=2 q \\
\sum_{i_{1} \neq i_{2} ; i_{1}, i_{2} \in G_{1}} n_{i_{2}} \geq n_{i_{1}}\left(v_{i_{1}}-2\right)+2 \quad \forall i_{1}, i_{2} \in G_{1}
\end{gathered}
$$

Eq. (2) ensures single bonds between groups. The parameter $n_{i}{ }^{(1)}$ is the number of first-order groups $G_{1}$ of set $i$ in the target molecule, $v_{i}$ the valency of group $i$ and $q$ is assigned the value of 1,0 or -1 for acyclic, monocyclic 
or bicyclic groups, respectively. Bicyclic groups require additional constraints. Additional constraints were placed on the number $\left(n_{i}^{(1)}\right)$ of groups to keep it within lower and upper bounds, $n_{i}{ }^{L}$ and $n_{i}{ }^{U}$, respectively:

$$
n_{i_{1}}^{L} \leq n_{i_{1}} \leq n_{i_{1}}^{U}
$$

A further constraint was placed on the total number of groups making up a given molecule:

$$
n^{L} \leq \sum_{i_{1} \in G_{1}} n_{i_{1}} \leq n^{U}
$$

Eqs. (1)-(4) are valid for structural combination of first order molecular groups. However, these equations are only sufficient to describe acyclic molecules or monocyclic molecules with no branches. Thus, additional equations for this work were required. They were defined to allow for bicyclic and branched cyclic molecules with and without side branches. An equation was defined for structural constraints of alicyclic groups for monocyclic and bicyclic type:

$$
\begin{gathered}
n^{L} \leq \sum_{i_{1} \in G_{\text {Alicyclic }}} n_{i} \leq\left(n^{U}-\left(n^{U}-2\right) q\right) \\
-2 q \leq n_{C H_{(c y c)}}
\end{gathered}
$$

Similarly, equations were defined for aromatic monocyclic and bicyclic molecules:

$$
\begin{gathered}
\sum_{i_{1} \in G_{\text {Aromatic }}} n_{i}=6-4 q \\
-2 q \leq n_{a C}
\end{gathered}
$$

Further, an additional equation was defined for the number of branched chains on the cyclic molecule:

$$
\sum_{i_{1} \in G_{\text {Acyclic }}} n_{i_{1}} \leq n_{\text {branch }}^{U}\left(\sum_{i_{1} \in\left\{G_{\text {Alicyclic }}, G_{\text {Aromatic }} \mid v_{i_{1}} \geq 3\right\}} n_{i_{1}}\left(v_{i_{1}}-2\right)+2 q\right)
$$

To ensure at least one fluorine and a double bond was present when a molecule with chlorine was designed, the following constraints were also included:

$$
\begin{aligned}
& Y_{C l}=\sum_{i_{1} \in G_{\text {Chlorine }}} n_{i} \\
& Y_{C l} \leq \sum_{i_{1} \in G_{\text {Fluorine }}} n_{i} \\
& Y_{C l} \leq \sum_{i_{1} \in G_{\text {DoubleBonds }}} n_{i} \\
& Y_{C l} \in\{0,1\}
\end{aligned}
$$

The SRK EoS equation was utilized [23,35]. Its equations were provided in the supplementary material, Eqs. (7)-(12). 


\subsection{ORC unit model}

The target for the process is to maximize the net power output, which is the difference between the turbine power and pump power:

$$
\dot{W}_{\text {net }}=\dot{W}_{\text {Turbine }}-\dot{W}_{\text {pump }}
$$

This can be reformulated into an expression based on working fluid enthalpies:

$$
\max \dot{W}_{n e t}=F_{r}\left(\left(h_{6,2}-h_{7,2}\right)-\left(h_{2,1}-h_{1,1}\right)\right)
$$

The remaining equations for the ORC unit model are given in the supplementary material. Energy balances over the heat exchangers were defined for flow rate and UA calculation. The general equations used for the UA calculations (Eq. 14 and 15) were complemented by the equations given in the supplementary material:

$$
\begin{gathered}
U A=\frac{\dot{Q}}{L M T D}=\frac{F\left(h_{\text {in }}-h_{\text {out }}\right)}{L M T D} \\
U A_{\text {boiler }}=U A_{\text {preheater }}+U A_{\text {evaporator }}+U A_{\text {superheater }}
\end{gathered}
$$

\subsection{Mixed-integer nonlinear program for integrated design}

Out of the molecular groups selected for design, six group contributions were missing for $T_{c}, P_{c}$ and $\omega$. The missing group contributions were calculated using the GC+ method and are provided in Table 4 using data from Hukkerikar et al. (2012).

Table 4: Estimated group contributions for missing groups using [24] method

\begin{tabular}{|l|l|l|l|}
\hline Group $\boldsymbol{i}_{1}$ & $\mathbf{T}_{\text {ci1 }}$ & $\mathbf{P}_{\text {ci1 }}$ & $\boldsymbol{\omega}_{\text {i1 }}$ \\
\hline $\mathbf{C C l}_{\mathbf{2}}$ & 5.85 & 0.03 & 0.08 \\
\hline $\mathbf{C F}$ & 0.89 & 0.02 & 0.05 \\
\hline $\mathbf{H C C l F}$ & 3.49 & 0.04 & \\
\hline $\mathbf{C =}_{(\text {cyc) }}$ & 2.35 & 0.01 & \\
\hline $\mathbf{C F}_{\text {2cyc }}$ & 1.4 & & \\
\hline $\mathbf{C F}_{\text {cyc }}$ & 1.3 & 0.02 & \\
\hline
\end{tabular}

The resulting mathematical program is a mixed-integer nonlinear program (MINLP). The model has 85 variables (21 discrete) and 132 constraints with 1112 Jacobian elements, 396 of which were nonlinear. The Hessian of the Lagrangian has 57 diagonal elements, 360 elements below the diagonal, and 67 nonlinear variables.

\subsection{Software}

The solution to the MINLP requires selection of a solution strategy and solver. LINDOGlobal was selected as the MINLP solver for the simultaneous solution strategy, being a global optimal solver that was documented 
to find global optimal solution even for possibly non-convex problems [36]. The software used was GAMS [37], into which the MINLP was implemented.

\section{Results and discussion}

The solution of the MINLP containing the fluid design model and cycle model is summarized in Table 5. The solutions obtained were in three parts; first the program solved for acyclic molecules, then alicyclic molecules and finally aromatic molecules. The results suggest that the optimal solution for an acyclic molecule is a hydrofluorocarbon giving 1.21 MW of net power output. The acyclic and aromatic solutions have slightly lower objective function values of 1.20 MW and 1.05 MW, respectively. The two cyclic compounds require sub-atmospheric pressure conditions in the condenser, althoug they require similar operational conditions in the cycle compared to the acyclic solution. The acyclic solution gives excellent environmental properties with a zero ODP and very low GWP value. To the best of our knowledge, the acyclic fluid is not available in any commercial or in-house databases. However, the synthesis could be performed from a hexane backbone or a double deoxygenation reaction of 2,2,3,3,4,4,5,5-Octafluoro-1,6-hexanediol, which is a common fluid (National Center for Biotechnology Information). The other two designed fluids are novel as well. In an industrial setting, these fluids need to be synthesized and then subsequently analyzed to obtain experimental properties before being tested in a pilot and full-scale organic Rankine cycle process.
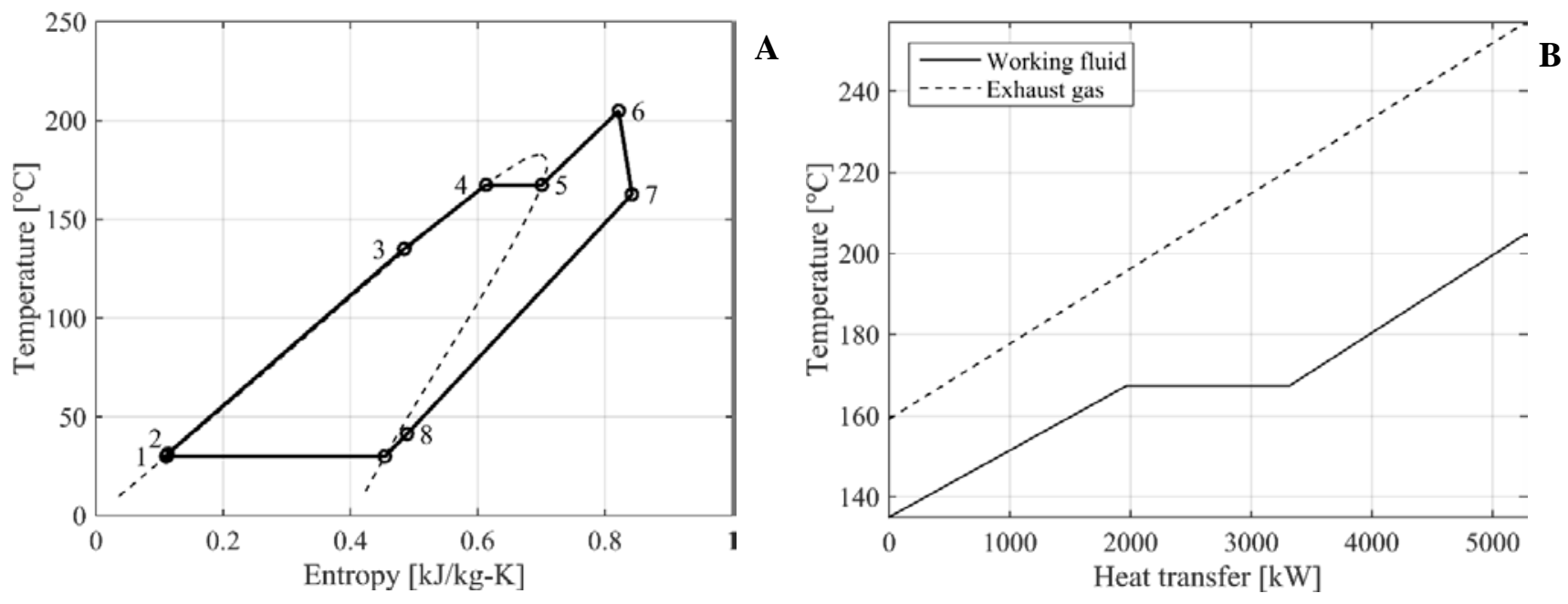

Figure 3: Diagrams for optimal acyclic solution. T-S diagram (A) and Q-T diagram (B).

Figure 3 (A) T-S-diagram for the ORC unit. The number on the diagram indicates the stages in the cycle. In Figure 3 (B) Q-T diagram for the boiler. 
Table 5: Simultaneous optimization results with pinch-point constraints

\begin{tabular}{|c|c|c|c|}
\hline Variable & Acyclic & Alicyclic & Aromatic \\
\hline Structure & \begin{tabular}{l|l} 
& \\
$\mathrm{H}_{3} \mathrm{C}-\mathrm{F}$ & \\
$\mathrm{F}$ & $\mathrm{F}$ \\
$\mathrm{F}-\mathrm{F}$ & $\mathrm{F}$ \\
& $\mathrm{F}$ \\
& $\mathrm{CH}$
\end{tabular} & & $\mathrm{CH}_{3}$ \\
\hline $\mathbf{n}_{1}$ & 2 CH3; 4 CF2 & 2 CH3; 1 CH: 3 CF2сус; 1 CFсус & 3 aCH; 1 aC-CH3; 2 aC-F \\
\hline IUPAC & $\begin{array}{l}\text { 2,2,3,3,4,4,5,5- } \\
\text { octafluorohexane }\end{array}$ & $\begin{array}{l}\text { 1,1,2,2,3,3,4-heptafluoro-4- } \\
\text { (propan-2-yl)cyclobutane }\end{array}$ & $\begin{array}{l}\text { 1,2-difluoro-6- } \\
\text { methylcyclohexa-1,3-diene }\end{array}$ \\
\hline $\mathbf{q}$ & 1 & 0 & 0 \\
\hline$\dot{\mathbf{W}}_{\text {net }}(\mathrm{W})$ & $1,205,257$ & $1,198,266$ & $1,052,569$ \\
\hline $\mathbf{T}_{\mathrm{c}}(\mathrm{K})$ & 455.83 & 451.16 & 588.39 \\
\hline $\mathbf{P}_{c}$ (bar) & 30.69 & 24.45 & 36.84 \\
\hline$\omega$ & 0.20 & 0.32 & 0.32 \\
\hline GWP $\left(\mathrm{CO}_{2} \mathbf{e q}\right)$ & 5.88 & $-*$ & $-*$ \\
\hline ODP (R11eq) & 0 & $-*$ & $-*$ \\
\hline $\mathrm{C}_{\mathrm{p}, \mathrm{A}}$ & $-5 \mathrm{E}+01$ & $-2 \mathrm{E}+02$ & $-3 \mathrm{E}+02$ \\
\hline $\mathrm{C}_{\mathrm{p}, \mathrm{B}}$ & $1 \mathrm{E}+00$ & $2 \mathrm{E}+00$ & $2 \mathrm{E}+00$ \\
\hline $\mathrm{C}_{\mathrm{p}, \mathrm{C}}$ & $-1 \mathrm{E}-03$ & $-3 E-03$ & $-3 E-03$ \\
\hline $\mathrm{C}_{\mathrm{p}, \mathrm{D}}$ & 4E-07 & 1E-06 & 2E-06 \\
\hline $\mathbf{P}_{1}$ (bar) & 1.17 & 0.75 & 0.05 \\
\hline $\mathbf{P}_{2}$ (bar) & 24.55 & 19.56 & 2.49 \\
\hline $\mathbf{T}_{1}(\mathbf{K})$ & 303.15 & 303.15 & 311.75 \\
\hline $\mathbf{T}_{2}(\mathrm{~K})$ & 304.42 & 304.42 & 311.87 \\
\hline$T_{3}(K)$ & 408.15 & 408.15 & 408.15 \\
\hline $\mathbf{T}_{4}(\mathrm{~K})$ & 440.60 & 437.23 & 426.28 \\
\hline $\mathrm{T}_{6}(\mathrm{~K})$ & 478.04 & 485.16 & 476.28 \\
\hline $\mathrm{T}_{7}(\mathrm{~K})$ & 435.84 & 440.50 & 434.18 \\
\hline$T_{8}(K)$ & 314.42 & 314.42 & 321.87 \\
\hline$T_{g 1}(K)$ & 509.00 & 509.00 & 509.00 \\
\hline $\mathbf{T}_{\mathrm{g} 2}(\mathrm{~K})$ & 480.47 & 476.50 & 489.93 \\
\hline $\mathbf{T}_{\mathrm{g} 3}(\mathrm{~K})$ & 460.60 & 457.23 & 446.28 \\
\hline$T_{g 4}(K)$ & 432.37 & 433.26 & 438.77 \\
\hline$F_{\mathrm{r}}(\mathrm{mol} / \mathrm{s})$ & 154.12 & 138.11 & 91.60 \\
\hline $\mathrm{UA}_{\text {boiler }}(\mathrm{W} / \mathrm{K})$ & 191,453 & 192,338 & 128,689 \\
\hline $\begin{array}{l}\text { UA } \\
(\mathbf{W} / K)\end{array}$ & $343,236.12$ & $338,722.77$ & $188,646.89$ \\
\hline $\begin{array}{l}\text { UA } \\
(\mathbf{W} / \mathbf{K})\end{array}$ & $270,268.20$ & $225,186.86$ & $133,944.95$ \\
\hline
\end{tabular}




\subsection{Decomposed approach}

For analysis of all the results, a decomposed solution approach was used. Here, the the fluid mixed-integer linear program (MILP) problem is solved independently and subsequently each solution is fed to the cycle (nonlinear program (NLP)). For the decomposed solution approach, the BARON solver was used for the MILP [39] and CONOPT solver for the NLP [40]. A decomposed solution strategy was then applied The first problem is an MILP that contains the molecular structure constraints and property prediction constraints with the product-related targets (Eqs. (1)-(10) and Eqs. (1)-(18) in the supplementary material). For each solution, an NLP program was solved containing the remaining equations of the program (Eqs. (12)-(15) and Eqs. (19)(58) in the supplementary material). The result is that in total 9124 candidates were identidied, of which 2062 fluids were found feasible for the ORC The ten best results are given in Table 6. The results have been summarized only and the full list of results is provided in the supplementary material.

Table 6: Decomposed solution strategy using pinch-point optimization

\begin{tabular}{|l|l|l|l|l|l|l|l|l|l|l|}
\hline Solution & $\dot{\mathbf{W}}_{\text {net }}(\mathbf{W})$ & $\mathbf{T}_{\mathbf{c}}(\mathbf{K})$ & $\mathbf{P}_{\mathbf{c}}(\mathbf{b a r})$ & $\mathbf{\omega}$ & $\mathbf{P}_{\mathbf{1}}(\mathbf{b a r})$ & $\mathbf{P}_{\mathbf{2}}(\mathbf{b a r})$ & $\mathbf{T}_{\mathbf{1}}(\mathbf{K})$ & $\mathbf{T}_{\mathbf{6}}(\mathbf{K})$ & $\mathbf{T}_{\mathbf{g} 4}(\mathbf{K})$ & $\mathbf{F}_{\mathbf{r}}(\mathbf{m o l} / \mathbf{s})$ \\
\hline acyclic3588 & $1,205,256$ & 455.83 & 30.69 & 0.203 & 1.17 & 24.55 & 303.15 & 478.04 & 432.37 & 154.11 \\
\hline acyclic6209 & $1,171,494$ & 597.66 & 95.61 & 0.126 & 0.23 & 6.52 & 303.15 & 464.00 & 430.74 & 121.65 \\
\hline acyclic6207 & $1,170,371$ & 597.22 & 91.38 & 0.142 & 0.20 & 6.22 & 303.15 & 465.36 & 431.44 & 118.10 \\
\hline acyclic4600 & $1,170,320$ & 599.44 & 43.88 & 0.183 & 0.07 & 2.58 & 303.15 & 464.68 & 431.06 & 112.40 \\
\hline acyclic4600 & $1,170,320$ & 599.44 & 43.88 & 0.183 & 0.07 & 2.58 & 303.15 & 464.68 & 431.06 & 112.40 \\
\hline acyclic4262 & $1,169,981$ & 594.00 & 99.80 & 0.114 & 0.28 & 7.03 & 303.15 & 461.56 & 429.56 & 126.64 \\
\hline acyclic4262 & $1,169,960$ & 594.00 & 99.80 & 0.114 & 0.28 & 7.03 & 303.15 & 461.57 & 429.56 & 126.63 \\
\hline acyclic4467 & $1,169,125$ & 598.73 & 42.19 & 0.206 & 0.06 & 2.35 & 303.15 & 464.28 & 430.84 & 109.86 \\
\hline acyclic6426 & $1,168,849$ & 591.98 & 41.16 & 0.205 & 0.07 & 2.59 & 303.15 & 464.82 & 431.08 & 111.28 \\
\hline acyclic6067 & $1,168,368$ & 586.30 & 90.68 & 0.136 & 0.26 & 6.84 & 303.15 & 461.81 & 429.64 & 125.08 \\
\hline
\end{tabular}

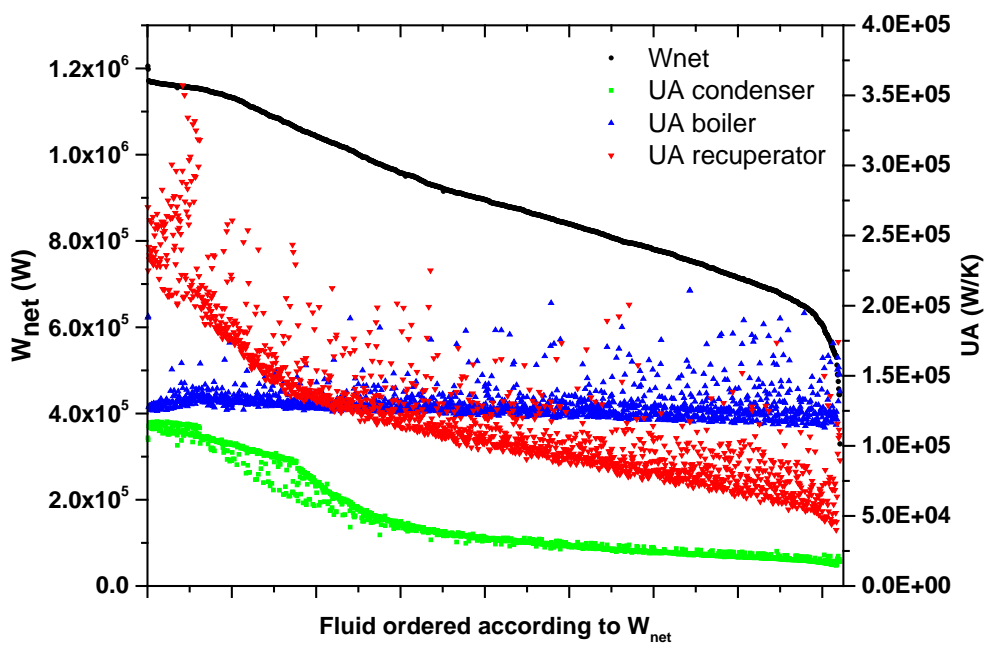

Figure 4: Decomposition results for $\dot{W}_{\text {net }}$ optimization and resulting UA values. The results are ordered on the x-axis from fluid with highest $\dot{W}_{\text {net }}$ to the fluid with the lowest $\dot{W}_{\text {net }}$. 
As expected, the highest net power output is achieved by an acyclic fluid and this matches the solution from the simultaneous solution approach. Figure 4 shows the entire spectrum of the objective function plotted against UA values for the heat exchangers. The figure indicated little correlation between the ORC performance and UA boiler size. However, a clear relation is seen with the condenser and recuperator UA values.

The case study clearly demonstrates the successful application of the integrated approach. Additionally, the decomposition data suggest that the best result matches the simultaneous approach and finds all possible solutions, although at the expense of extra resources. In the following section, the simultaneous and decomposed approach will be compared. The correlation between product properties and process variables will be discussed to support the decision made with respect to the simultaneous approach that has been proposed. Finally, an alternative optimization strategy will be presented, given the arguments on the issue with sensitivity between $\dot{W}_{\text {net }}$ and UA-values.

\subsection{Comparison with conventional approaches}

The decomposed approach represents a conventional approach where, given a set of heuristic criteria, a set of feasible fluids are generated or selected. Subsequently, each fluid may be tested, designed and optimized in the cycle $[15,41]$.

\subsubsection{Decomposed approach}

The simultaneous solution approach solved the entire MINLP simultaneously. The decomposed solution solved the product MILP and a subset of process NLP for each candidate fluid. This results in an equal separation of blocks of equations as given in Table 7. In addition, continuous and discrete variables are given separately. Cumulatively, the number of variables in the MILP and NLP are larger than in the simultaneous MINLP due to the number of common variables. Product properties that are not constrained are calculated in post-phase as described in Table 7. The difference in number of equations and variables is not necessarily negative, although it is clear that the resources required are significantly different (See Table 1 in the supplementary material). The time for solving the MINLP is 5.04 seconds. However, the solution time for finding all the 9124 fluid candidates is 5760 seconds (1.60 hours) and the resulting computation time for solving the NLP for all the ORC unit is 15002 seconds (4.18 hours). Thus, the total time for solving the decomposition problem is 20762 seconds (5.78 hours). The simultaneous solution is therefore the least computationally expensive.

Table 7: Resources and program information for simultaneous and decomposed solution approach

\begin{tabular}{|l|l|l|l|l|}
\hline Metric & $\begin{array}{l}\text { Simultaneous } \\
\text { MINLP }\end{array}$ & $\begin{array}{l}\text { Product } \\
\text { MILP }\end{array}$ & $\begin{array}{l}\text { Post-calculation of each } \\
\text { fluid }\end{array}$ & $\begin{array}{l}\text { Process } \\
\text { NLP }\end{array}$ \\
\hline $\begin{array}{l}\text { Blocks of } \\
\text { equations }\end{array}$ & 79 & $19 *$ & 6 & 54 \\
\hline $\begin{array}{l}\text { Blocks of } \\
\text { variables }\end{array}$ & 21 & 7 & 6 & 17 \\
\hline Discrete variables & 21 & 21 & 0 & 0 \\
\hline * Excluding one equation for a dummy objective function \\
\hline
\end{tabular}


The argument for using simultaneous optimization is that the resources and time required is greatly reduced, because the high sensitivity between the two design problems requires a wide search space resulting in a combinatorial explosion. This sensitivity is illustrated in Figure 5 where three contours are plotted based on the decomposition results. In Figure $5 \mathrm{~A}$ the sensitivity of $T_{c}, P_{c}$ and $\dot{W}_{\text {net }}$ is shown and it can be deduced that there is no definite area where a specific combination of the two properties provide a high value of the objective function. On the contrary, the gradients indicate a high correlation that result in several scattered areas that have $\dot{W}_{\text {net. }}$ The same is seen in Figure 5.B with $\omega$ and $T_{c}$ and in Figure 5.C with $P_{c}$ and $\omega$. In Figure 5, the numbers closest to 1 or -1 have the strongest correlation and any element that is higher than 0.5 or lower than -0.5 is marked red. It can be seen that there is a high correlation between several variables. Such as the correlation between $\dot{W}_{\text {net }}$ with $U A_{\text {boiler }}$ (low), $U A_{\text {condenser }}$ (high) and $U A_{\text {recuperator }}$ (high), which matches with the observations made in the case study result of Figure 4. A correlation is also observed between the common variables and the process variables, such as $T_{c}$ with $U A_{\text {boiler }}$ and $T_{c}$ with $\mathrm{P}_{1}$. Thus, a decomposed approach is a sub-optimal approach because the fluid properties cannot be correlated with the process performance, therefore requiring that all feasible fluids to be tested. 


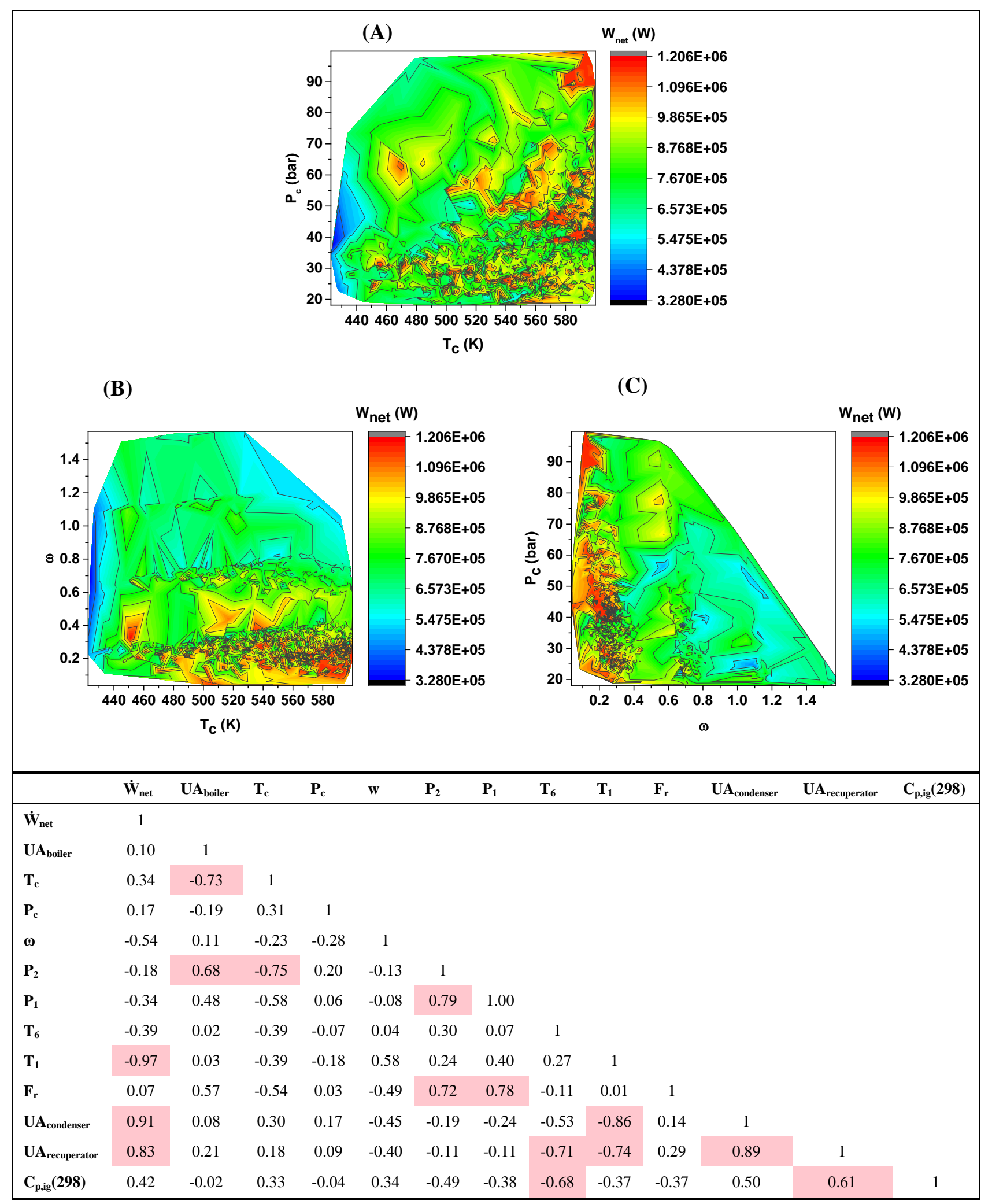

Figure 5: Cross-correlation for solution candidates obtained from the decomposed solution approach 


\subsubsection{Heuristic selection of fluids}

Alternatives to the decomposition method also exist. For example, a heuristic selection of a set of known refrigerants is a common method. However, this inherently leads to a sub-optimal design route because of the limited availability of fluids (due to regulations) and due to the fact that no specific set of property values can give an indication of the process performance. In the following it is shown that a selection of the conventionally highest performing refrigerants does not perform as well as the design solution found in this paper.

The global optimal fluid (2,2,3,3,4,4,5,5-octafluorohexane) designed in the case study employing pinch point constraints was compared with conventional fluids used in similar ORC unit applications. The conventional fluids were selected from the scientific literature [33]. The fluids were compared on the basis of three selected process metrics: Net power output, pressure ratio and degree of superheating, where the reference value of unity is relative to the global optimal fluid designed in the present study. Net power output directly indicates the performance of the cycle. A high pressure ratio can have a negative influence on the expander performance and/or expander cost. The degree of superheating is related to the heat transfer area, and therefore by implication to investment cost, for the boiler, since the heat transfer performance of vapour superheating is poor. In the comparison (Figure 6), it can be seen that the generated fluid in this resulting from the current work outperforms the conventional fluids, but it also has one of the highest pressure ratios whilst keeping a low degree of superheating. However, it is worth noting that MM has more than a three-fold higher pressure ratio than the generated fluid. The low superheating is good since it means improved heat utilization and lower heat exchanger area requirements.

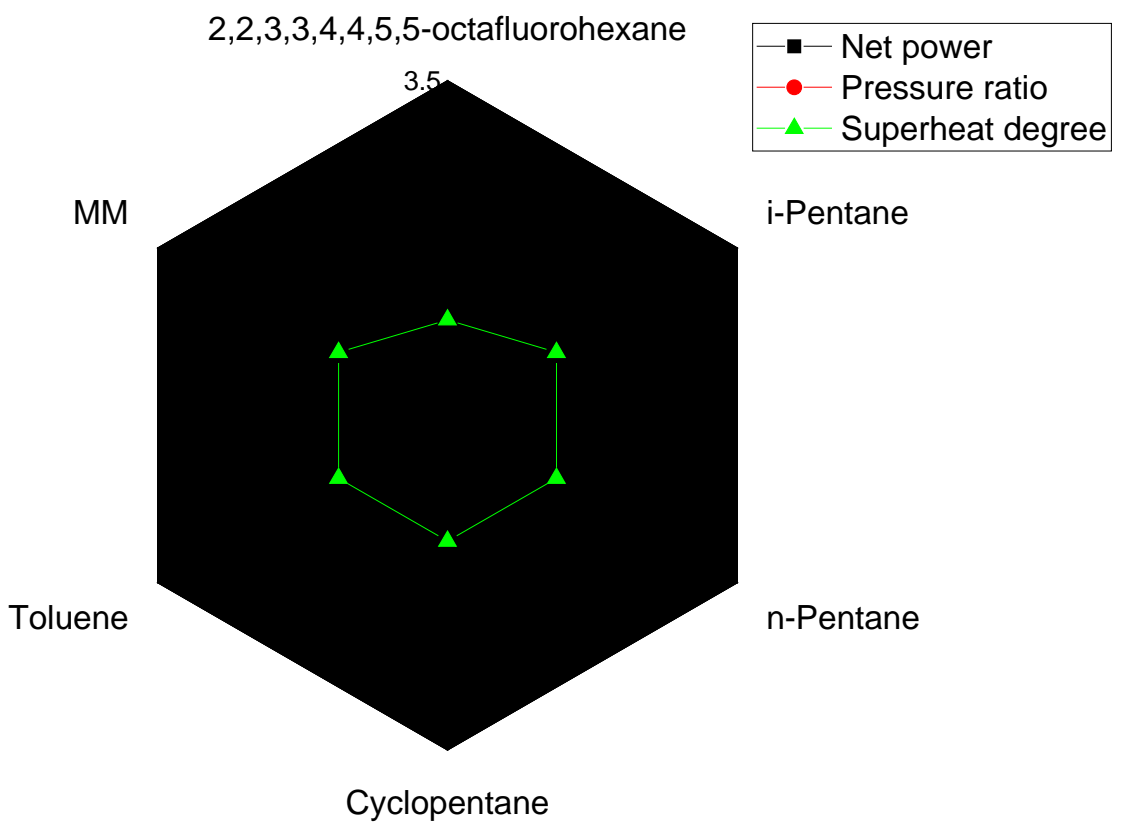

Figure 6: Optimal fluid comparison against benchmarks 


\subsubsection{Continuous-molecular targeting approach (CoMT-CAMD)}

CoMT-CAMD methods are used when the combined product and process model is infeasible to solve simultaneously. In this way, the integer variables of molecular design are relaxed to obtain a continuous NLP that is easier to solve than the complete MINLP. Subsequently, molecules must be designed that have the same (or close to) relaxed molecular properties. However, since the simultaneous optimization of the fluid and cycle is possible in the case presented here, such approaches are not needed. Nevertheless, the information obtained from such a study is valuable, in that the optimal theoretical properties can be identified. In optimization, this is also termed a 'relaxed' solution. Additionally, the approach can give a good indication of the theoretical maximum objective function achievable, for a given problem. In this case, it provides an indication of how close the optimal solution from the simultaneous or decomposed solution approach is to the theoretical maximum. In order to illustrate this, a study was performed with the model and conditions presented in this paper. For the program this meant that the 21 discrete variables become free variables. This was solved and it was found that the maximum objective function was 1.6 MW, which as expected is higher than the result obtained by other methods. The product properties are given in Table 8 .

Table 8: Relaxed fluid design properties with a CoMT-CAMD approach

\begin{tabular}{|l|l|l|l|l|}
\hline & $\mathrm{T}_{\mathrm{c}}(\mathrm{K})$ & $\mathrm{P}_{\mathrm{c}}(\mathrm{bar})$ & $\omega(-)$ & $\mathrm{W}_{\text {net }}(\mathrm{MW})$ \\
\hline Relaxed solution & 469.77 & 37.81 & 1 & 1.6 \\
\hline $\begin{array}{l}\text { Closest integer solution 1: } \\
\text { 2 CH3, 1 CH2F, 1 CF, 1 CF2 }\end{array}$ & 462.22 & 33.69 & 0.70 & 0.7 \\
\hline $\begin{array}{l}\text { Closest integer solution 2: } \\
\text { 2 CH3, 1 CH2, 1CF, 1CHF2 }\end{array}$ & 468.24 & 30.84 & 0.72 & 0.6 \\
\hline $\begin{array}{l}\text { Closest integer solution 3: } \\
\text { 1 CH3, 1 1CH2=CH, 1 CF, 1 CHF2 }\end{array}$ & 469.69 & 31.89 & 0.70 & 0.6 \\
\hline
\end{tabular}

The ideal gas heat capacity coefficients have no physical meaning and had to be fixed for a known fluid, here the optimal fluid from Table 5,. It is clear that the acentric factor has hit the upper bound. However, the marginal value reported by the solver is small $(65 \mathrm{~kW})$. This indicates that increasing the bound for the acentric factor would not improve the results significantly. From the databases used in this work, no fluid reported had an acentric factor higher than unity [7]. Using the CoMT-CAMD method, the task was then to find a pure fluid that matches those property values as closely as possible. With the product design MILP model used in this work (Eqs. (1)-(10) and in supplementary material Eqs. (1)-(12)), the closest integer solutions were found and are reported in Table 9. The search space was constrained to narrow down the search around the relaxed solution: $T_{c}$ between 460 and $470 \mathrm{~K}, \mathrm{P}_{\mathrm{c}}$ between 28 and 48 bar and $\omega$ between 0.4 and 1 . However, running the ORC process design optimization the designed fluid showed that the optimal objective function is $0.7 \mathrm{MW}$ for integer solution 1 . This is significantly lower than that given by the relaxed solution. The remaining two solutions gave 0.6 MW. This illustrates how important the values of the pure properties are, even though they cannot be clearly correlated with the process performance. Although more integer solutions close to the relaxed solution point could be investigated and optimized in the process, this study indicates that the simultaneous approach is preferred.

\subsection{UA-optimization strategy}

The high correlation between $\dot{W}_{\text {net }}$ and $U A_{\text {recuperator }}$ and $U A_{\text {condenser }}$ with $T_{c}$ and $U A_{\text {boiler }}$ indicate that it would be favorable to employ a new optimization strategy for this case study result. Rather than basing the optimization on the lower bound for the pinch points in the heat exchangers to reduce the capital cost, an upper bound on 
the UA values could be imposed instead. This would potentially address the issues with the high correlation. Furthermore, the designed optimal fluid is dependent on the process targets, in addition to the product targets. Thus, a pinch-point or UA-constrained method may yield different optimal fluids. In the current study this was demonstrated by employing UA constraints on the boiler and recuperator. The condenser was still modelled by considering a constant condensation temperature. The upper bounds were based on the pinchpoint optimization results and were selected as $1.9 * 10^{\wedge} 5 \mathrm{~W} / \mathrm{K}$ and $2.6 * 10^{\wedge} 5 \mathrm{~W} / \mathrm{K}$ for the boiler and the recuperator, respectively. The decomposed approach was also used in this case and the results depicted in Figure 7. A similar profile is seen for the objective function, although now the upper bounds are reached for the UA constraints. This is now a comparable result for each fluid since the UA sizes are the same, with minor outliers. With this, a simultaneous solution strategy was used taking the new UA bounds. The results are summarized in Table 9. As shown, different results are now obtained, due to the inclusion of UA bounds, and a new fluid with a higher objective function than obtained previously observed.

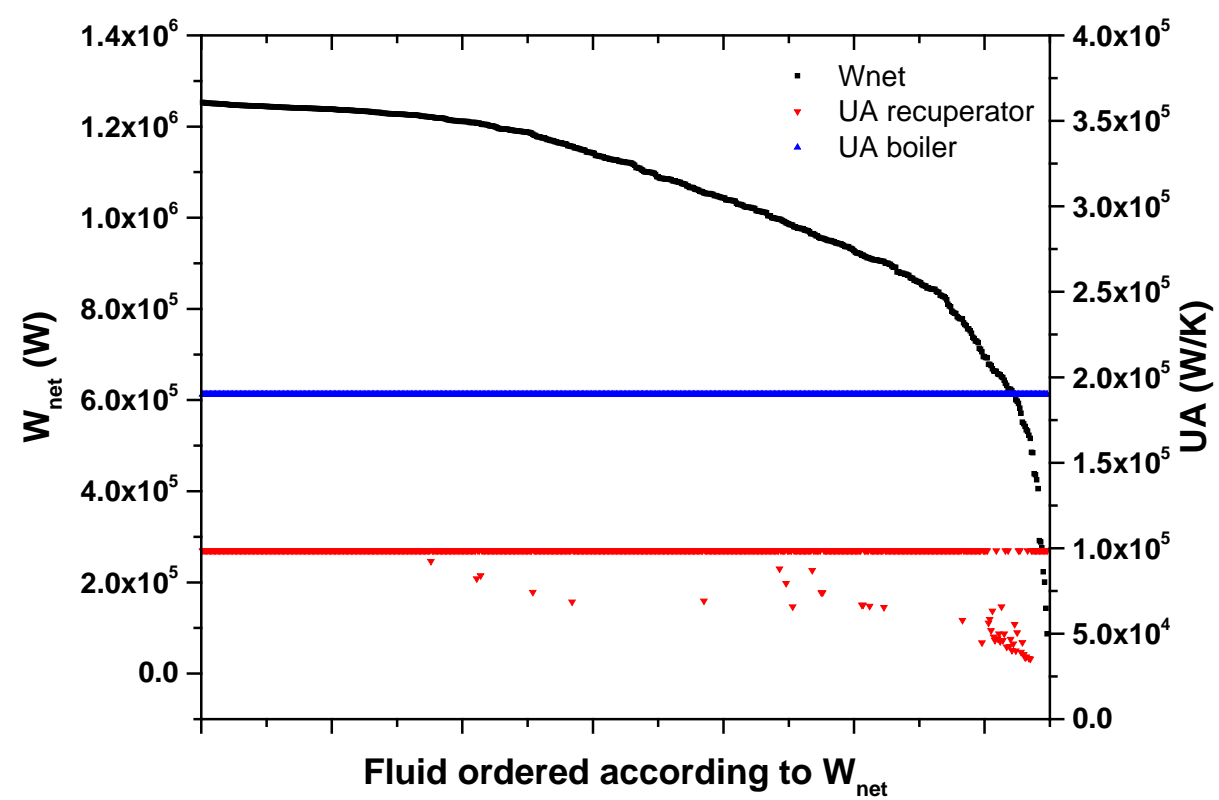

Figure 7: Decomposed optimization with UA-based strategy 
Table 9: Simultaneous optimization results with UA value constraints. GWP and ODP are omitted, as they cannot be calculated with any of the generated groups.

\begin{tabular}{|c|c|c|c|}
\hline Variable & Acyclic & Alicyclic & Aromatic \\
\hline Structure & $=<_{\mathrm{F}}^{\mathrm{CH}_{3}}$ & $\mathrm{H}_{3} \mathrm{C}$ & $\mathrm{H}_{3} \mathrm{C}-\mathrm{CH}_{3}$ \\
\hline $\mathbf{n}_{1}$ & $\begin{array}{l}3 \text { CH3; } 1 \text { C=C; } 1 \text { CHF; } 1 \\
\text { CClF2 }\end{array}$ & $\begin{array}{l}2 \mathrm{CH} 3 ; 1 \mathrm{CH} 2 ; 1 \mathrm{CH} 2 \text { (сус); } 1 \\
\text { С(сус); } 1 \mathrm{CH}=\mathrm{CH}(\text { сус) }\end{array}$ & 3 CH3; 1 aC-C; 5 aC-F \\
\hline IUPAC & $\begin{array}{l}\text { 5-chloro-4,5,5-trifluoro-2,3- } \\
\text { dimethylpent-2-ene }\end{array}$ & $\begin{array}{l}\text { 3-ethyl-3-methylcyclobut-1- } \\
\text { ene }\end{array}$ & $\begin{array}{l}\text { 1-tert-butyl-2,3,4,5,6- } \\
\text { pentafluorobenzene }\end{array}$ \\
\hline $\mathbf{q}$ & 1 & 0 & 0 \\
\hline$\dot{\mathbf{W}}_{\text {net }}(\mathrm{W})$ & $1,253,071$ & $1,256,810$ & 936,343 \\
\hline $\mathbf{T}_{\mathrm{c}}(\mathbf{K})$ & 595.99 & 586.80 & 588.81 \\
\hline $\mathbf{P}_{\mathrm{c}}$ (bar) & 29.61 & 33.26 & 21.21 \\
\hline$\omega$ & 0.188 & 33.261 & 0.467 \\
\hline $\mathrm{C}_{\mathrm{p}, \mathrm{A}}$ & -88.23 & -137.77 & -458.53 \\
\hline $\mathrm{C}_{\mathrm{p}, \mathrm{B}}$ & 1.30 & 1.26 & 3.50 \\
\hline$C_{p, C}$ & $-1.36 \mathrm{E}-03$ & $-1.37 \mathrm{E}-03$ & $-5.02 E-03$ \\
\hline $\mathbf{C}_{\mathrm{p}, \mathrm{D}}$ & $5.30 \mathrm{E}-07$ & $9.56 \mathrm{E}-07$ & 2.55E-06 \\
\hline $\mathbf{P}_{1}$ (bar) & 0.05 & 0.06 & 0.05 \\
\hline $\mathbf{P}_{2}$ (bar) & 3.64 & 3.89 & 2.23 \\
\hline$T_{1}(K)$ & 303.16 & 303.15 & 339.14 \\
\hline $\mathbf{T}_{2 \mathrm{r}}(\mathrm{K})$ & 303.35 & 303.38 & 339.27 \\
\hline $\mathbf{T}_{3}(\mathrm{~K})$ & 408.15 & 408.15 & 408.15 \\
\hline $\mathbf{T}_{5}(\mathbf{K})$ & 448.28 & 440.25 & 456.29 \\
\hline $\mathbf{T}_{6}(\mathrm{~K})$ & 477.77 & 483.70 & 461.29 \\
\hline $\mathbf{T}_{7 \mathrm{r}}(\mathbf{K})$ & 428.14 & 429.96 & 425.09 \\
\hline $\mathbf{T}_{8}(\mathrm{~K})$ & 307.94 & 305.93 & 341.95 \\
\hline$T_{g 1}(K)$ & 509.00 & 509.00 & 509.00 \\
\hline $\mathrm{T}_{\mathrm{g} 2}(\mathrm{~K})$ & 496.86 & 492.55 & 506.84 \\
\hline $\mathbf{T}_{\mathrm{g} 3}(\mathrm{~K})$ & 456.05 & 450.16 & 462.66 \\
\hline $\mathbf{T}_{\mathrm{g} 4}(\mathrm{~K})$ & 437.87 & 436.97 & 438.52 \\
\hline $\mathrm{F}_{\mathrm{r}}(\mathrm{mol} / \mathrm{s})$ & 101.48 & 104.88 & 87.35 \\
\hline $\begin{array}{l}\text { UA boiler } \\
\text { (W/K) }\end{array}$ & 190,000 & 190,000 & 190,000 \\
\hline $\begin{array}{l}\text { UA } \\
\text { (W/K) }\end{array}$ & 375,437 & 377,798 & 343,235 \\
\hline $\begin{array}{l}\mathbf{U A}_{\text {recuperator }} \\
\text { (W/K) }\end{array}$ & 270,000 & 270,000 & 270,000 \\
\hline
\end{tabular}




\subsection{SWOT analysis}

The main contribution of the paper is the new simultaneous design method for the working fluid and organic Rankine cycle. Therefore, the method is now SWOT analyzed to further illustrate its benefits and limitations. The analysis is given in Table 10.

Table 10: SWOT analysis

\begin{tabular}{|c|c|}
\hline Strengths & Weaknesses \\
\hline $\begin{array}{l}\text { - Fluid and cycle can simultaneously be } \\
\text { designed and optimized. } \\
\text { - The design time is much lower compared to } \\
\text { conventional methods. } \\
\text { - The design solution in the case shown here } \\
\text { was globally optimal, which would not have } \\
\text { been possible with other methods. }\end{array}$ & $\begin{array}{l}\text { - The method requires a model for both the } \\
\text { fluid design and the cycle process. } \\
\text { - The problems need to be well bounded and } \\
\text { a feasible initial point is needed. } \\
\text { - The method is prone to uncertainties, as with } \\
\text { any prediction method. }\end{array}$ \\
\hline Opportunities & Threats \\
\hline $\begin{array}{l}\text { - New types of fluids can be designed that } \\
\text { otherwise would not have been selected by } \\
\text { heuristics. } \\
\text { - The fluids designed can either be completely } \\
\text { novel or be available from other application } \\
\text { areas. } \\
\text { - More sustainable fluids can be designed that } \\
\text { comply with international regulations. }\end{array}$ & $\begin{array}{l}\text { - The decomposed method can be preferred } \\
\text { when all feasible fluid designed solutions } \\
\text { are desired, e.g. for sensitivity studies. } \\
\text { - Use of more complex and high fidelity } \\
\text { thermodynamic models or process models } \\
\text { can make the simultaneous solution of the } \\
\text { MINLP infeasible. }\end{array}$ \\
\hline
\end{tabular}

\section{Conclusions}

The presented approach designed a working fluid and ORC unit that performs better than conventional fluids in terms of net power output and environmental properties with respect to global warming potential and ozone depletion potential. Furthermore, a relaxed design problem solution indicates that the problem bounds are reasonable and that the optimal solution is close to the theoretical maximum. The high sensitivity between fluid and cycle design variables experienced for state-of-the-art methods was overcome with the simultaneous approach presented and applied in this paper. Furthermore, the sensitivity is quantified and analyzed using a decomposition solution strategy where all feasible solutions were obtained. It was shown that this sensitivity could be addressed by employing a proposed UA-bound optimization strategy. The results suggest that the optimal fluid is 2,2,3,3,4,4,5,5-octafluorohexane (1.2 MW) using the simultaneous approach and fixed pinch points, and 5-chloro-4,5,5-trifluoro-2,3-dimethylpent-2-ene (1.25 MW) with the simultaneous approach and UA-bound optimization strategy. Thus, this paper presents an approach to overcome many challenges in fluidcycle design and can likely be applied in other types of cycle as well.

\section{Acknowledgements}

This work was supported by the Danish Council for Strategic Research in Sustainable Energy and Environment under the THERMCYC project (grant number 1377-00037A). 
For the formulation of the equations of bicyclic and branched cyclic molecules (Eqs. (5)-(9)), the authors would like to thank Associate Professor Lei Zhang from Dalian University of Technology, China, for the initial formulation of the equations.

\section{References}

[1] United Nations Environment Programme, Kyoto Protocol to the United Nations Framework Convention On Climate Change, (1997) 1-24.

[2] M. Schulz, D. Kourkoulas, REGULATION (EU) No 517/2014 OF THE EUROPEAN PARLIAMENT AND OF THE COUNCIL of 16 April 2014 on fluorinated greenhouse gases and repealing Regulation (EC) No 842/2006, Off. J. Eur. Union. (2014) L150/195-230.

[3] A. Mota-Babiloni, J. Navarro-Esbrí, Á. Barragán-Cervera, F. Molés, B. Peris, Analysis based on EU Regulation No 517/2014 of new HFC/HFO mixtures as alternatives of high GWP refrigerants in refrigeration and HVAC systems, Int. J. Refrig. 52 (2015) 21-31. doi:10.1016/j.jirefrig.2014.12.021.

[4] S. Cignitti, J. Frutiger, B. Zühlsdorf, F. Bühler, J.G. Andreasen, F. Müller, F. Haglind, B. Elmegaard, J. Abildskov, G. Sin, J. Woodley, Forbedring af industrielle processers energieffektivitet, Dansk Kemi. 97 (2016) 10-12.

[5] H. Chen, D.Y. Goswami, E.K. Stefanakos, A review of thermodynamic cycles and working fluids for the conversion of low-grade heat, Renew. Sustain. Energy Rev. 14 (2010) 3059-3067. doi:10.1016/j.rser.2010.07.006.

[6] B.F. Tchanche, G. Lambrinos, A. Frangoudakis, G. Papadakis, Low-grade heat conversion into power using organic Rankine cycles - A review of various applications, Renew. Sustain. Energy Rev. 15 (2011) 3963-3979. doi:10.1016/j.rser.2011.07.024.

[7] E.W. Lemmon, M.L. Huber, M.O. McLinden, NIST Standard Reference Database 23: Reference Fluid Thermodynamic and Transport Properties, version 9.1, Natl. Inst. Stand. Technol. (2013). doi:10.1234/12345678.

[8] J.S. Brown, Hfos new, low global warming potential refrigerants, ASHRAE J. 51 (2009) 22-29.

[9] M.E. Mondejar, S. Cignitti, J. Abildskov, J.M. Woodley, F. Haglind, Prediction of properties of new halogenated olefins using two group contribution approaches, Fluid Phase Equilib. (2016). doi:10.1016/j.fluid.2016.10.020.

[10] J. Navarro-Esbrí, J.M. Mendoza-Miranda, a. Mota-Babiloni, a. Barragán-Cervera, J.M. BelmanFlores, Experimental analysis of R1234yf as a drop-in replacement for R134a in a vapor compression system, Int. J. Refrig. 36 (2013) 870-880. doi:10.1016/j.ijrefrig.2012.12.014.

[11] L. Zhang, S. Cignitti, R. Gani, Generic mathematical programming formulation and solution for computer-aided molecular design, Comput. Chem. Eng. 78 (2015) 79-84. doi:10.1016/j.compchemeng.2015.04.022.

[12] A.I. Papadopoulos, M. Stijepovic, P. Linke, P. Seferlis, S. Voutetakis, Power generation from low enthalpy geothermal fields by design and selection of efficient working fluids for organic Rankine cycles, Chem. Eng. Trans. 21 (2010) 61-66. doi:10.3303/CET10210011.

[13] A.I. Papadopoulos, M. Stijepovic, P. Linke, On the systematic design and selection of optimal working fluids for Organic Rankine Cycles, Appl. Therm. Eng. 30 (2010) 760-769. doi:10.1016/j.applthermaleng.2009.12.006.

[14] A.I. Papadopoulos, M. Stijepovic, P. Linke, P. Seferlis, S. Voutetakis, Multi-level Design and Selection of Optimum Working Fluids and ORC Systems for Power and Heat Cogeneration from Low Enthalpy Renewable Sources, Elsevier B.V., 2012. doi:10.1016/B978-0-444-59519-5.50014-9.

[15] O. Palma-Flores, A. Flores-Tlacuahuac, G. Canseco-Melchor, Optimal molecular design of working fluids for sustainable low-temperature energy recovery, Comput. Chem. Eng. 72 (2015) 334-349. doi:10.1016/j.compchemeng.2014.04.009.

[16] J.G. Andreasen, U. Larsen, T. Knudsen, L. Pierobon, F. Haglind, Selection and optimization of pure 
and mixed working fluids for low grade heat utilization using organic Rankine cycles, Energy. 73 (2014) 204-213. doi:10.1016/j.energy.2014.06.012.

[17] M. Lampe, M. Stavrou, H. Bücker, Simultaneous Optimization of Working Fluid and Process for Organic Rankine Cycles (ORCs) using PC-SAFT, Ind. Eng. Chem. Res. 53 (2014) 8821-8830. http://pubs.acs.org/doi/abs/10.1021/ie5006542 (accessed November 28, 2014).

[18] M. Lampe, M. Stavrou, J. Schilling, E. Sauer, J. Gross, A. Bardow, Computer-aided molecular design in the continuous-molecular targeting framework using group-contribution PC-SAFT, Elsevier Ltd, 2015. doi:10.1016/j.compchemeng.2015.04.008.

[19] D. Roskosch, B. Atakan, Reverse engineering of fluid selection for thermodynamic cycles with cubic equations of state, using a compression heat pump as example, Energy. 81 (2015) 202-212. doi:10.1016/j.energy.2014.12.025.

[20] R. Prapainop, K.O. Suen, Effects of refrigerant properties on refrigerant performance comparison: A review, Int. J. Eng. Res. Appl. 2 (2012) 486-493. http://www.ijera.com/papers/Vol2_issue4/BV24486493.pdf.

[21] J. Bao, L. Zhao, A review of working fluid and expander selections for organic Rankine cycle, Renew. Sustain. Energy Rev. 24 (2013) 325-342. doi:10.1016/j.rser.2013.03.040.

[22] S. Cignitti, L. Zhang, R. Gani, Computer-aided Framework for Design of Pure, Mixed and Blended Products, 12th Int. Symp. Process Syst. Eng. 25th Eur. Symp. Comput. Aided Process Eng. 37 (2015) 2093-2098. doi:10.1016/B978-0-444-63576-1.50043-1.

[23] G. Soave, Equilibrium constants from a modified Redlich-Kwong equation of state, Chem. Eng. Sci. 27 (1972) 1197-1203. doi:10.1016/0009-2509(72)80096-4.

[24] A.S. Hukkerikar, B. Sarup, A. Ten Kate, J. Abildskov, G. Sin, R. Gani, Group-contribution + (GC +) based estimation of properties of pure components: Improved property estimation and uncertainty analysis, Fluid Phase Equilib. 321 (2012) 25-43. doi:10.1016/j.fluid.2012.02.010.

[25] K.G. Joback, R.C. Reid, Estimation of Pure-Component Properties From Group-Contributions, Chem. Eng. Commun. 57 (1987) 233-243. doi:10.1080/00986448708960487.

[26] D. Di Battista, M. Mauriello, R. Cipollone, Waste heat recovery of an ORC-based power unit in a turbocharged diesel engine propelling a light duty vehicle, Appl. Energy. 152 (2015) 109-120. doi:10.1016/j.apenergy.2015.04.088.

[27] J. Song, C. wei Gu, Performance analysis of a dual-loop organic Rankine cycle (ORC) system with wet steam expansion for engine waste heat recovery, Appl. Energy. 156 (2015) 280-289. doi:10.1016/j.apenergy.2015.07.019.

[28] E. Wang, Z. Yu, H. Zhang, F. Yang, A regenerative supercritical-subcritical dual-loop organic Rankine cycle system for energy recovery from the waste heat of internal combustion engines, Appl. Energy. 190 (2017) 574-590. doi:10.1016/j.apenergy.2016.12.122.

[29] MAN Diesel \& Turbo, CEAS Engine Calculation Tool, (2017). www.marine.man.eu/two-stroke/ceas (accessed February 28, 2017).

[30] S. by Aic. Design Institute for Physical Properties, DIPPR Project 801 - Full Version, 2005. http://app.knovel.com/web/toc.v/cid:kpDIPPRPF7/viewerType:toc/root_slug:dippr-project-801-full.

[31] J. Frutiger, J. Abildskov, G. Sin, Global sensitivity analysis of computer-aided molecular design problem for the development of novel working fluids for power cycles, Comput. Aided Chem. Eng. 38 (2016) 283-288. doi:10.1016/B978-0-444-63428-3.50052-7.

[32] MAN Diesel \& Turbo, Soot deposits and fires in exhaust gas boilers, 2014.

[33] J. Andreasen, A. Meroni, F. Haglind, A Comparison of Organic and Steam Rankine Cycle Power Systems for Waste Heat Recovery on Large Ships, Energies. 10 (2017) 547. doi:10.3390/en10040547.

[34] O. Odele, S. Macchietto, Computer aided molecular design: a novel method for optimal solvent $\begin{array}{llllll}\text { selection, } & \text { Fluid } & \text { Phase } & \text { Equilib. } & 82 & \text { (1993) }\end{array}$ http://www.sciencedirect.com/science/article/pii/037838129387127M.

[35] Y. Rao, Chemical engineering thermodynamics, Universities Press, 1997. 
[36] Y. Lin, L. Schrage, The global solver in the LINDO API, Optim. Methods Softw. 24 (2009) 657-668. doi:10.1080/10556780902753221.

[37] M. Bussieck, A. Meeraus, General algebraic modeling system (GAMS), Appl. Optim. 88 (2004) 137158. doi:10.1007/978-1-4613-0215-5_8.

[38] National Center for Biotechnology Information, PubChem Compound Database; CID=136181, 2017. (n.d.). https://pubchem.ncbi.nlm.nih.gov/compound/136181 (accessed February 28, 2017).

[39] N. V. Sahinidis, BARON: A general purpose global optimization software package, J. Glob. Optim. 8 (1996) 201-205. doi:10.1007/BF00138693.

[40] A.S. Drud, CONOPT -- A Large-Scale GRG Code, ORSA J. Comput. 6 (1994) 207-216. doi:10.1287/ijoc.6.2.207.

[41] A.P. Duvedi, L.E.K. Achenie, Designing environmentally safe refrigerants using mathematical programming, Chem. Eng. Sci. 51 (1996) 3727-3739. doi:10.1016/0009-2509(96)00224-2. 